J. L. Ding*, K. C. Liu**, and C. R. Brinkman"*

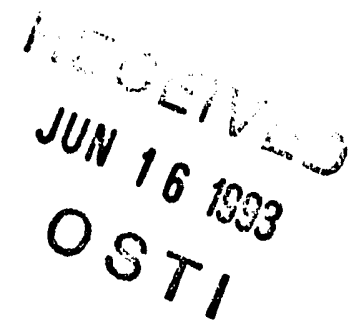

\title{
MULTIAXIAL DEFORMATION AND LIFE PREDICTION MODEL AND EXPERIMENTAL DATA FOR ADVANCED BILICON NITRIDE CERAMIC8
}

REFERENCE: Ding, J. L., Liu, K. C. and Brinkman, C. R. "Multiaxial Deformation and Life Prediction Model and Experimental Data for Advanced silicon Nitride Ceramics," Life Prediction Methodologies and Data for Ceramic Materials, ASTM STP 1201, C. R. Brinkman, and S. F. Duffy, Eds., American Society for Testing and Materials, Philadelphia, 1993.

ABSTRACT: The current paper summarizes recent experimental results on creep and creep rupture behavior of a commercial grade of $\mathrm{Si}_{3} \mathrm{~N}_{4}$ ceramic in the temperature range of $1150^{\circ} \mathrm{C}$ to $1300^{\circ} \mathrm{C}$ obtained at Oak Ridge National Laboratory; and introduces a tentative multiaxial deformation and life prediction model for ceramic materials under general thermomechanical loadings. Issues related to the possible standardization of the data analysis methodology and possible future research needs for high temperature structural ceramics in the area of development of data base and life prediction methodology are also discussed.

REYWORDS: silicon nitride, creep, creep-rupture, constitutive equations, multiaxial deformation

\section{INTRODUCTION}

Demonstrated improvements in materials processing technology have shown advanced silicon nitride ceramics to be

- Professor, Department of Mechanical and Materials Engineering, Washington State University, Pullman, WA 991642920.

* Senior Scientist and Group Leader, respectively, Oak Ridge National Laboratory, Metals and Ceramics Division, Oak Ridge, TN 37831 .

\section{MASTER}

The submitted manuscript has been authored by contractor of the U.S. authored by under contract No DEGovernment under contract Noly, the U.S ACO5-840R2 1400. Accordingly, hor U. Government retains a nonexclusive, royalty-troe license to publish or reproduce the published form of this contribution, of allow others to do so, for U.S. Government 
feasible structural materials for many engineering applications at high temperatures. Because these materials are relatively new and less traditional, development of a reliable material data base and a new deformation and life prediction methodology are also necessary in order to improve the rellability of ceramic components.

In the past, creep properties of ceramics have been studied predominantly using flexure tests. Information on the creep behavior of ceramics under pure uniaxial loading conditions is very 1 imited. In a recent study [1], the creep and creep rupture properties of a commercial grade of $\mathrm{Si}_{3} \mathrm{~N}_{4}$ ceramic were systematically characterized in the temperature range of $1150^{\circ} \mathrm{C}$ to $1300^{\circ} \mathrm{C}$. Based on these data, a high temperature deformation and life prediction model for ceramic materials under general thermomechanical loading condition was proposed [2]. The model was in the form of scalar equations. The current paper summarizes key results obtained in Refs. 1 and 2 , and in addition, proposes a possible extension of the model from the scalar equations to tensorial equations. Based on the experimental and theoretical results obtained to date, issues related to the standard analysis of the creep data and possible future research needs for high temperature structural ceramics in the area of development of data base and life prediction methodology are also discussed.

\section{MATERIAL, SPECIMEN, AND EXPERIMENTAL APPARATUS}

The material studied in the current work was a commercial grade of hot-isostatically-pressed (HIP) $\mathrm{Si}_{3} \mathrm{~N}_{4}$ containing $\mathrm{Y}_{2} \mathrm{O}_{3}$ and $\mathrm{SrO}$ as densification aids. It is designated $\mathrm{GN}-10$ and was produced by Garrett Ceramic Components Division of AlliedSignal Aerospace Company of Los Angeles, California.

The specimen used was a buttonhead tensile specimen whose geometry and surface finish was described in [1]. Creep tests were performed on four standard lever-arm creep testing machines. The specimen was loaded by dead weight via a lever arm. To maintain a uniform tensile stress in the test specimen, self aligning gripping fixtures [3], developed at ORNL, were incorporated in the loading train. A low-profile, two-zone-controlled resistance furnace capable of achieving temperatures to $1600^{\circ} \mathrm{C}$ was used to heat the specimen. The temperature along the gage section was measured with three thermocouples, one placed near the middle and one near each end of the gage length. The temperature gradient between the center and the end of the gage section was less than 0.58 of the maximum temperature at the center. Creep strain was measured by a mechanical extensometer developed at ORNL [4]. The extensometer has a resolution of 5 microstrain and an absolute accuracy better than 100 microstrain for long term creep testing. 


\section{EXPERIMENTAL DATA}

(1) Creep and Creep Rupture Behavior of The As-HIPed Material

The test matrix for the creep tests performed and the resultant rupture times are shown in (Table 1). The corresponding creep curves are shown in Figs. 1 to 4. The symbols in these figures represent the experimental data and the solid lines are the model predictions which will be discussed later.

ORNL DWG $92 \cdot 13+43 R 1$

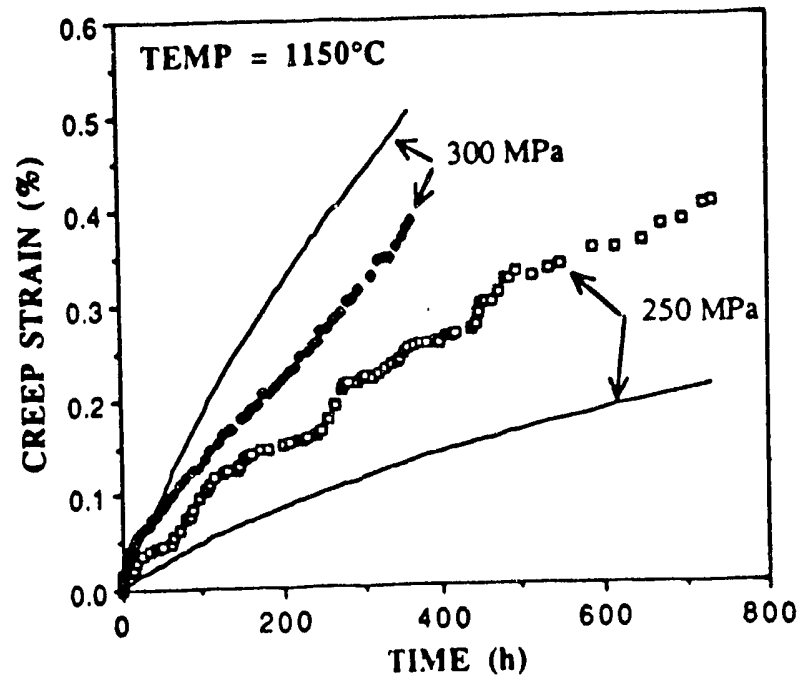

FIG. 1--Creep curves of $\mathrm{GN}-10 \mathrm{Si}_{3} \mathrm{~N}_{4}$ tested at $1150^{\circ} \mathrm{C}$. symbols are experimental data, and solid lines are predictions of the proposed model at the indicated stresses.

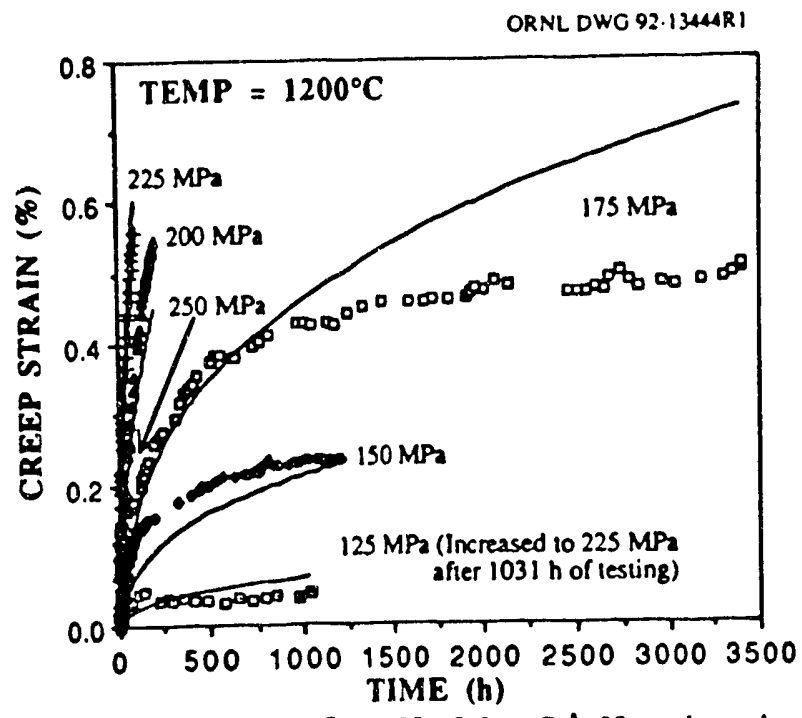

FIG. 2--Creep curves of $\mathrm{GN}-10 \mathrm{Si}_{3} \mathrm{~N}_{4}$ tested at $1200^{\circ} \mathrm{C}$. symbols are experimental data, and solid lines are predictions of the proposed model at the indicated stresses. 
ORNL DWG 92.13446RI

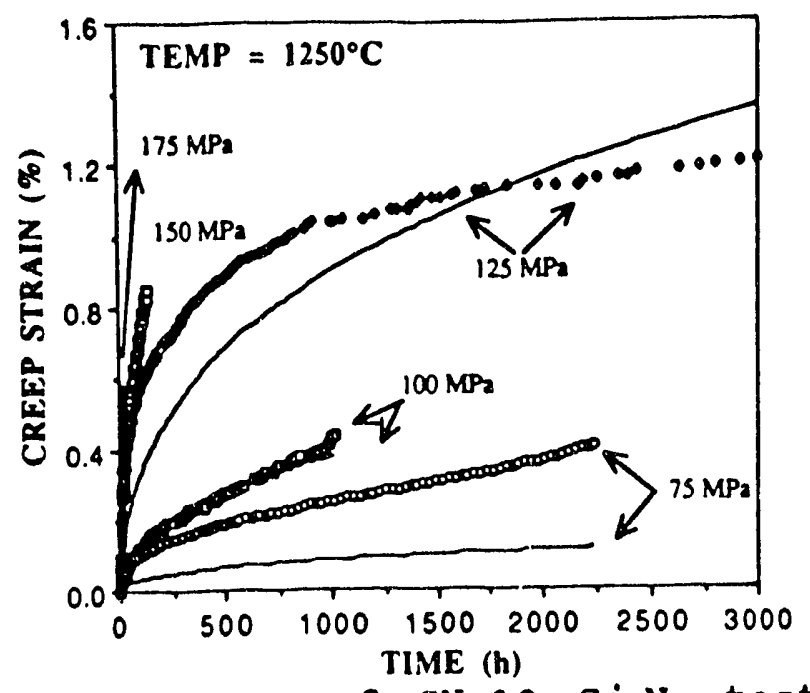

FIG. 3--creep curves of $\mathrm{GN}-10 \mathrm{Si}_{3} \mathrm{~N}_{4}$ tested at $1250^{\circ} \mathrm{C}$. symbols are experimental data, and solid lines are predictions of the proposed model at the indicated stresses.

ORNL DWG 92.13448RI

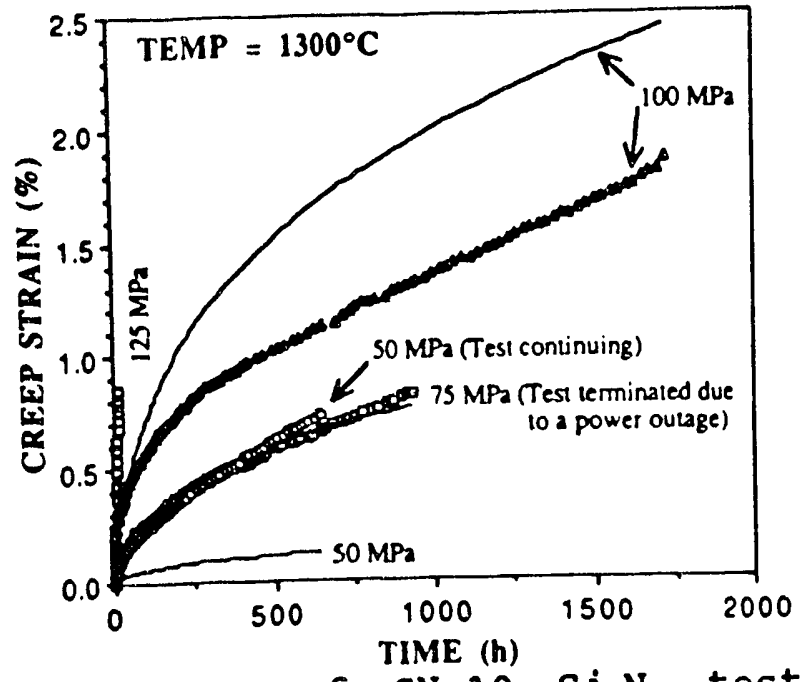

FIG.4--Creep curves of $\mathrm{GN}-10 \mathrm{Si}_{3} \mathrm{~N}_{4}$ tested at $1300^{\circ} \mathrm{C}$. Symbols are experimental data, and solid lines are predictions of the proposed model at the indicated stresses.

The two characteristic features of the overall creep behavior of $\mathrm{GN}-10 \mathrm{Si}_{3} \mathrm{~N}_{4}$ exhibited in Figs. 1 to 4 are the lack of tertiary creep and the strong nonlinearity of the creep behavior with respect to both stress and temperature. The former is self-explanatory. The latter can be seen from the sharp transition in both creep behavior and rupture time with respect to a relatively small change of stress or temperature when the combination of stress and temperature reaches a certain level. For example, testing at $1300^{\circ} \mathrm{C}$ showed a sharp change in the creep behavior when the applied stress was 
increased from 100 to $125 \mathrm{MPa}$ (Fig. 4). The sharp transition was discerned to have occurred between 125 and $150 \mathrm{MPa}$ at $1250^{\circ} \mathrm{C}$ (Fig. 3) and between 175 and $200 \mathrm{MPa}$ at $1200^{\circ} \mathrm{C}$ (Fig. 2). At $1150^{\circ} \mathrm{C}$, because there are only two data points at relatively high stress levels, the transition region is not clear, but is probably somewhere between 200 and $250 \mathrm{MPa}$. Also, a comparison of the creep curves at $1250^{\circ} \mathrm{C}$ and $1300^{\circ} \mathrm{C}$, using data obtained at $125 \mathrm{MPa}$ as an example, revealed that a $50^{\circ} \mathrm{C}$ temperature difference has a significant effect on both the creep rate and rupture time.

Analysis of the creep rupture behavior indicated that the creep rupture time $(t)$ generally decreases with an increase in stress except in three cases where $t$ values at $1250^{\circ} \mathrm{C}$ under both $75 \mathrm{MPa}$ and $100 \mathrm{MPa}$ were shorter compared with that under $125 \mathrm{MPa}$; similarly $t_{r}$ at $1200^{\circ} \mathrm{C}$ under $150 \mathrm{MPa}$ was shorter compared with that under $175 \mathrm{MPa}$. It should be mentioned that the specimens tested at $1250^{\circ} \mathrm{C}$ under both 75 and $100 \mathrm{MPa}$ fractured at the shank as also indicated in (Table 1). The premature fracture is believed to be due to an inhomogeneous distribution of defects. In general, for most engineering materials, especially brittle materials such as ceramics, some scatter in $t_{r}$ as a function of stress is not unusual.

(2) Effects of Prior Creep And Annealing (Aging) on subsequent Creep Behavior

In metals, a decrease in creep rate during primary creep is usually attributed to an increase in the density and interaction of dislocations, i.e. strain hardening. In ceramics, dislocation activity occurring inside the matrix grains does not contribute significantly to creep deformation $[5,6]$. The major strengthening mechanism in $\mathrm{GN}-10 \mathrm{Si}_{3} \mathrm{~N}_{4}$ was found to be devitrification of the grain boundary phase by high temperature annealing for long times. Fig. 5 shows a comparison between the creep behavior of the as-HIPed material tested at $1200^{\circ} \mathrm{C}$ under $225 \mathrm{MPa}$ and that of a specimen precrept at $125 \mathrm{MPa}$ for $1031 \mathrm{~h}$ prior to the application of additional load to $225 \mathrm{MPa}$, (see Fig. 2). To facilitate comparison, the zero time for the precrept specimen was reset at the beginning of the second loading to $225 \mathrm{MPa}$. Although the precept specimen fractured prematurely at the buttonhead, the enhancement in creep resistance exhibited by the precept specimen is clearly discernable. Since the total creep strain accumulated during low stress creep was only 0.0448 , the strengthening was attributed to thermal annealing instead of strain hardening. 
ORN DWG 93.13450R

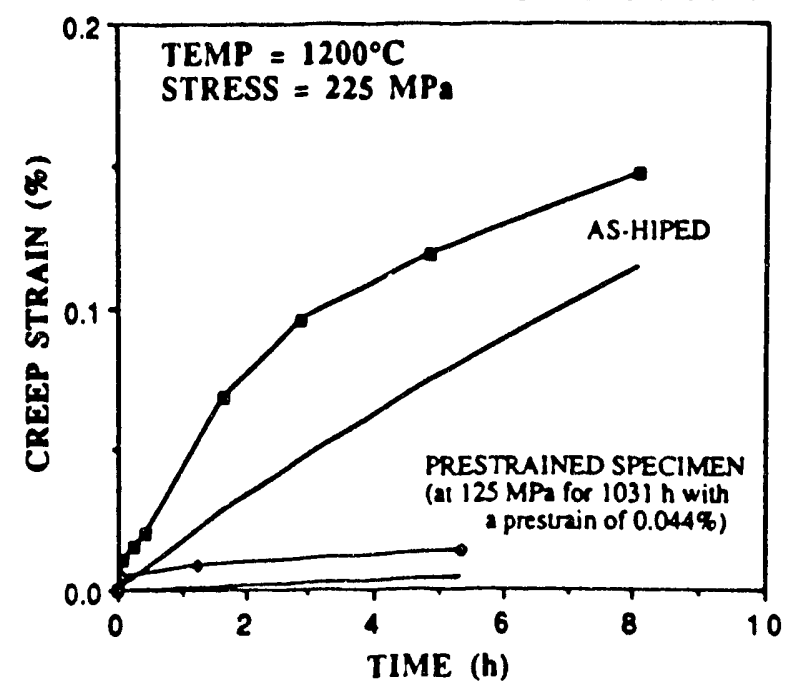

FIG. 5--Comparison of initial transient creep behavior of a specimen tested in the as-HIPed condition and that of a specimen precrept at $125 \mathrm{MPa}$ for $1031 \mathrm{~h}$. Both specimens were tested at $1200^{\circ} \mathrm{C}$ under $225 \mathrm{MPa}$. Symbols are experimental data, and solid lines are predictions of the proposed model.

To further study the devitrification induced strengthening due to thermal annealing, four specimens were annealed at $1370^{\circ} \mathrm{C}$ in air without applied stress for 150 hours. Creep curves were obtained for the annealed and the as-Hiped specimens at temperatures ranging from 1150 to $1300^{\circ} \mathrm{C}$. Fig. 6 is given as an example. A quantitative comparison was also made in Ref. 1. In general, thermal annealing enhanced both the creep resistance and rupture life of $\mathrm{GN}-10 \mathrm{Si}_{3} \mathrm{~N}_{4}$.

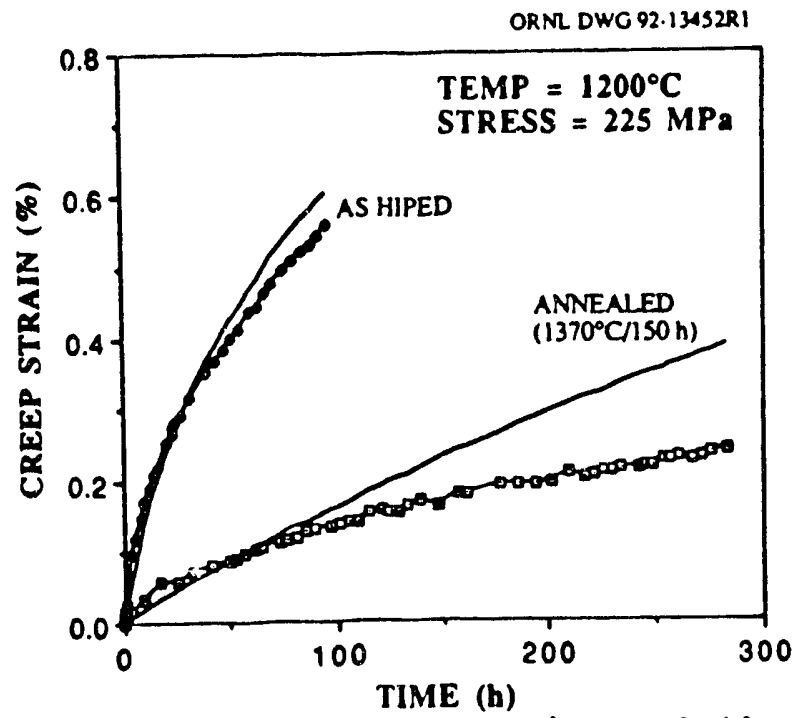

FIG. 6--Comparison of creep behavior of the annealed and as-HIPed specimens tested at $1200^{\circ} \mathrm{C}$ under $225 \mathrm{MPa}$. Symbols are experimental data, and solid lines are predictions of the proposed model. 


\section{TANDARD ANALY8IS OF THE CREEP AND CREEP RUPTURE DATA}

\section{(1) Analysis of The creer Data}

Most reported creep data on ceramics have been analyzed with Norton's power law relation described by

$$
e=A \sigma^{n} e^{-\frac{\rho}{A T}}
$$

where $d$ is the steady state creep rate, $\sigma$ is the stress, $T$ is the absolute temperature, $R$ is the gas constant, $Q$ is the activation energy, and $A$ and $n$ are material constants.

For a creep curve exhibiting three stages of creep, namely, primary, secondary, and tertiary creep, the steady state creep rate can be determined without any ambiguity as the creep rate at the transition to tertiary creep. It is obvious that the steady state creep rate is also the minimum creep rate during the entire creep process. For $G N-10 \quad S i_{3} N_{4}$ which does not exhibit tertiary creep or even steady state creep, there does not seem to be a common basis to objectively define the creep rates for determining Norton's relation. However, based on the facts that the steady state creep rate is equivalent to the minimum creep rate for a complete creep curve, and the minimum creep rate is achieved at the fracture point for a creep curve without the tertiary stage, creep rates at rupture time were tentatively used for the Norton relation for $G N-10 \quad \mathrm{Si}_{3} \mathrm{~N}_{4}$. Accordingly, the corresponding creep rate should probably be termed as the minimum creep rate instead of the steady state creep rate.

In [1], the minimum creep rates were determined by taking the time derivative of a curve fitting equation for all the creep curves at the rupture time or the end of each creep test. The equation is of the following form:

$$
e=x_{1}\left(\left(1+x_{2} t\right)^{x_{1}}-1\right)
$$

where $\epsilon$ is the creep strain, $t$ is the time, $x_{1}, x_{2}$ and $x_{3}$ are variables for curve fitting. It was found, in general that Eqn. (2) fit the creep data very well except for those at $1150^{\circ} \mathrm{C}$, and $300 \mathrm{MPa}$ and $1300^{\circ} \mathrm{C}, 100 \mathrm{MPa}$ in which a straight line seemed to better fit the latter stage of the experimental data [1]. Since Egn.(2) simulates a creep curve with an ever-decreasing (non-steady) creep rate, a good fit with the experimental data again implies that creep has probably not reached its steady state at fracture except for possibly the two aforementioned relatively poorly fitted creep curves. The calculated creep rates are plotted in Fig. 7 (a) and (b), in 
which open and closed symbols are used to represent the data above and below the aforementioned transition region respectively. For the interrupted tests and those in which the specimens were fractured at the shank as described in the footnotes of (Table 1), a downward arrow was also attached to the corresponding data point implying the actual creep rate might be lower than the indicated one. It is also clear from the data distribution shown in Fig. 7, that there is a wide blank band between the open and filled symbols. The band is essentially the aforementioned transition region across which there is a significant change in the creep rates.

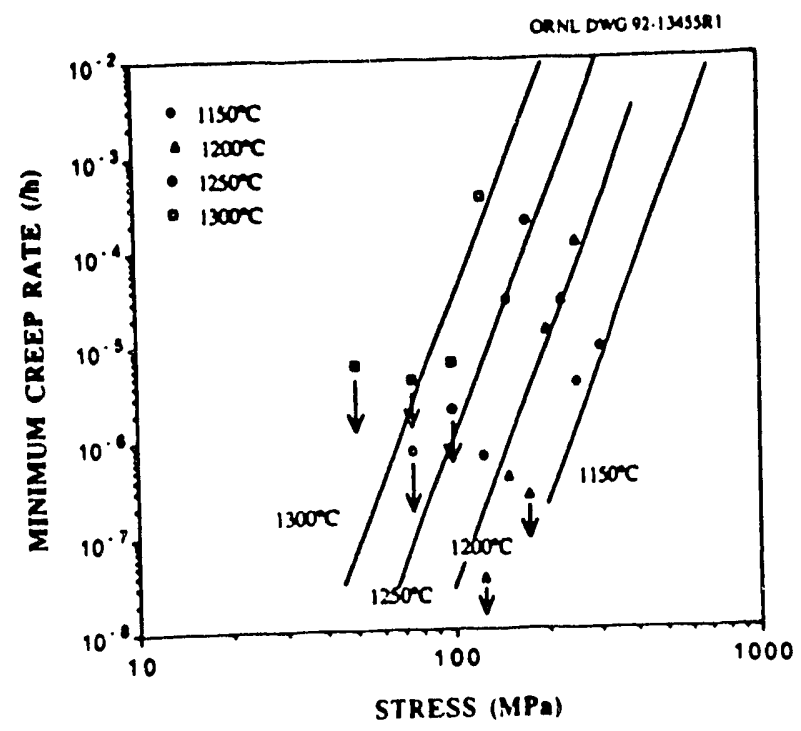

FIG. 7--(a) Comparison of the minimum creep rate data with Norton's power law relation (straight lines) with the stress exponent and activation energy equal to 8.4 and $1326 \mathrm{~kJ} / \mathrm{mole}$ respectively. Open and closed symbols represent the data above and below the experimentally observed transition region respectively. For the interrupted tests and those in which the specimens were fractured at the shank as described in the footnote of (Table 1), a downward arrow was also attached to the corresponding data point implying the actual creep rate might be lower than the indicated one. 


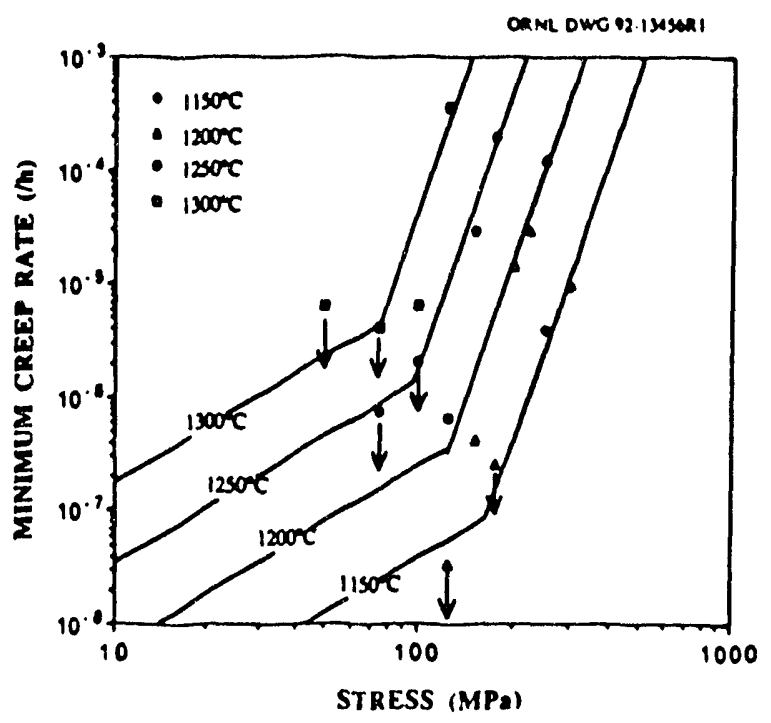

(b) Comparison of the minimum creep rate data with the bilinear (in log-log coordinates) Norton's power law relation. The transition points in terms of $(T, \sigma, k)$ are $\left(1150^{\circ} \mathrm{C}, 164\right.$ $\left.\mathrm{MPa}, 8.355 \times 10^{-8}\right),\left(1200^{\circ} \mathrm{C}, 125 \mathrm{MPa}, 3.453 \times 10^{-7}\right),\left(1250^{\circ} \mathrm{C}, 96\right.$ $\left.\mathrm{MPa}, 1.3 \times 10^{-6}\right),\left(1300^{\circ} \mathrm{C}, 76 \mathrm{MPa}, 4.501 \times 10^{\circ}\right)$. The stress exponent and the activation energy above and below the apparent transition points are 8.3 and $1292 \mathrm{~kJ} / \mathrm{mole}$, and 1.6 and $649 \mathrm{~kJ} / \mathrm{mole}$ respectively.

Two different approaches were used to analyze the creep rate data [1]. In the first approach, a multivariate regression analysis was simply performed on all the creep rate data, except for that from the test at $1300^{\circ} \mathrm{C} / 50 \mathrm{MPa}$ which is still continuing. The corresponding form for Norton's power law relation was found to be :

$$
e=e^{52.1} 0^{8.4} e^{-\frac{1326}{R T}}
$$

where $d$ is in $h^{-1}, \sigma$ in $M P a$, and $T$ in $K$. The stress exponent, $n$, and the activation energy, $Q$, are estimated to be 8.4 and $1326 \mathrm{~kJ} / \mathrm{mole}$ respectively. A comparison between the creep rate data and Eqn. (3) is shown in Fig. 7 (a).

It is well known that different deformation mechanisms may result in different rate equations [8]. Therefore, fitting all the creep rate data with a single power law relation somewhat implies that the dominant deformation mechanism may be the same for all the creep data. However, this seems to be contradictory to the experimental observations which showed a change in the creep behavior across a transition region. Therefore, in the second approach, the data above and below the apparent transition region were analyzed separately. Again with the multivariate regression analysis, it was found that 
the data (open symbols) above the transition region can be best described by :

$$
e=e^{50.5} 0^{8.3} e^{-\frac{1292}{R T}} ;
$$

and those below the transition region by :

$$
\varepsilon=e^{30.4} \sigma^{1.6} e^{-\frac{649}{R T}}
$$

In other words, the values of $n$ and $Q$ are 8.3 and 1292 $\mathrm{kJ} / \mathrm{mole}$, and 1.6 and $649 \mathrm{~kJ} / \mathrm{mole}$ for creep behavior above and below the transition region respectively. A comparison between the experimental data and Eqns. (4a) and (4b) are shown in Fig. 7b. The transition points determined from the above two equations in terms of $(T, \sigma, e)$ are $\left(1150^{\circ} \mathrm{C}, 164 \mathrm{MPa}, 8.355\right.$ $\left.\times 10^{-8} / \mathrm{h}\right),\left(1200^{\circ} \mathrm{C}, 125 \mathrm{MPa}, 3.453 \times 10^{\circ} / \mathrm{h}\right),\left(1250^{\circ} \mathrm{C}, 96 \mathrm{MPa}\right.$, $\left.1.300 \times 10^{-6} / \mathrm{h}\right)$, and $\left(1300^{\circ} \mathrm{C}, 76 \mathrm{MPa}, 4.501 \times 10^{-6} / \mathrm{h}\right)$.

As shown in Figs. $7 a$ and $7 b$, the distribution of the data below the transition region seems to be more random than those above. Or equivalently, the trend exhibited by the data on the bottom side does not appear to be as clear as that by those in the top. This may explain why both the $n$ and $Q$ values obtained from the data above the transition region, namely 8.3 and 1292 $\mathrm{kJ} / \mathrm{mole}$, are very close to those from the overall data, namely, 8.4 and $1326 \mathrm{~kJ} / \mathrm{mole}$. In other words, the values determined from the overall data may have been dominated by those above the transition region. Furthermore, quite a few of the data on the bottom side of Figs. $7 a$ and $7 b, i . e$. the data with an arxow attached, were from interrupted tests or those in which the specimens were fractured at the shank. Therefore, it should be cautioned that the values in Eqn. (4b) may be subjected to more uncertainty than those in Eqn. (4a). More data are definitely needed in order to clarify trends for the creep behavior below the apparent transition region.

In [9], $n$ and $Q$ were reported to be 5 and $1102 \mathrm{~kJ} / \mathrm{mole}$ respectively for $\mathrm{PY}-6 \mathrm{Si}_{3} \mathrm{~N}_{4}$ for data at $1260^{\circ} \mathrm{C}$ and $1370^{\circ} \mathrm{C}$, and an $n$ value of 16.1 was found for the data at $1150^{\circ} \mathrm{C}$. In [10], $n$ was found to be 6.9 for $\mathrm{NT}-154 \mathrm{Si}_{3} \mathrm{~N}_{4}$ tested between 1300 and $1400^{\circ} \mathrm{C}$ and 75 and $150 \mathrm{MPa}$. The activation energy was found to increase from $600 \mathrm{~kJ} / \mathrm{mole}$ for short term creep to $1250 \mathrm{~kJ} / \mathrm{mole}$ for long term creep. The current stress exponent $(n)$ and the activation energy (Q) for $\mathrm{GN}-10 \mathrm{Si}_{3} \mathrm{~N}_{4}$ determined from both the overall data and the data above the transition region seem to be very close to the above values, although the $n$ value is slightly higher than 5 or 6.9. The $n$ value below the transition region is close to that for diffusion creep, 1 .e. 1 , and the activation energy to that for viscous flow of the secondary phase in silicon nitride which is of the order of 
$600 \mathrm{~kJ} / \mathrm{mole}[11]$. In the relatively short term creep tests above the transition region, deformation is probably a stresscontrolled process. The relatively large $n$ value may indicate that creep deformation is attributed to stress-driven grain boundary sliding enhanced by some damage accumulation process such as slow crack growth. As mentioned earlier, there is some uncertainty in the values of $n$ and $Q$ determined from the data below the apparent transition region. However, if these values are indeed a good indication of the inherent deformation mechanism, the data may imply that for long term creep, deformation may have changed from a stress controlled process to a diffusion controlled one.

\section{(2) Analysis of Creep Rupture Data}

For predicting creep rupture life under isothermal and constant stress conditions, there are two popular models available, namely, the Larson-Miller model (LM) [12] and the minimum commitment method (MC) [13].

The Larson-Miller model [12] is described by the following equation:

$$
\log t_{x}=B_{0}+\frac{B_{1}}{T}+\frac{B_{2}}{T} \log \sigma_{1}
$$

where $t_{r}$ is the rupture time in hours, $\sigma$ is the stress in MPa, and $T$ is the absolute temperature in $K$. Using multivariate regression analysis, the model constants were determined as $B_{0}=-58.28, B_{1}=136600$ and $B_{2}=-20510$.

The minimum-commitment method [13] is described by the following equation:

$$
\log t_{x}+\left[R_{1}\left(T-T_{m}\right)+R_{2}\left(\frac{1}{T}-\frac{1}{T_{m}}\right)\right]=B+C \log \sigma+D \sigma+E \sigma^{2}
$$

where $T_{m}$ is the middle temperature of the temperature range used in the tests, or $1498 \mathrm{~K}$ in the current case. Again by multivariate regression analysis, the model constants were determined to be: $R_{1}=0.1731, \quad R_{2}=303700, B=87.24, C=-45.69$, $\mathrm{D}=0.1156, \mathrm{E}=-0.9733^{1} \times 10^{-4}$. A comparison of the experimental data and the model predictions is shown in Fig. 8. As described in the footnotes of (Table 1), the rupture time with a rightward arrow attached is probably shorter than the actual one because the tests were either interrupted or the specimens fractured somewhat prematurely. Therefore, these data were excluded in the above regression analysis. 


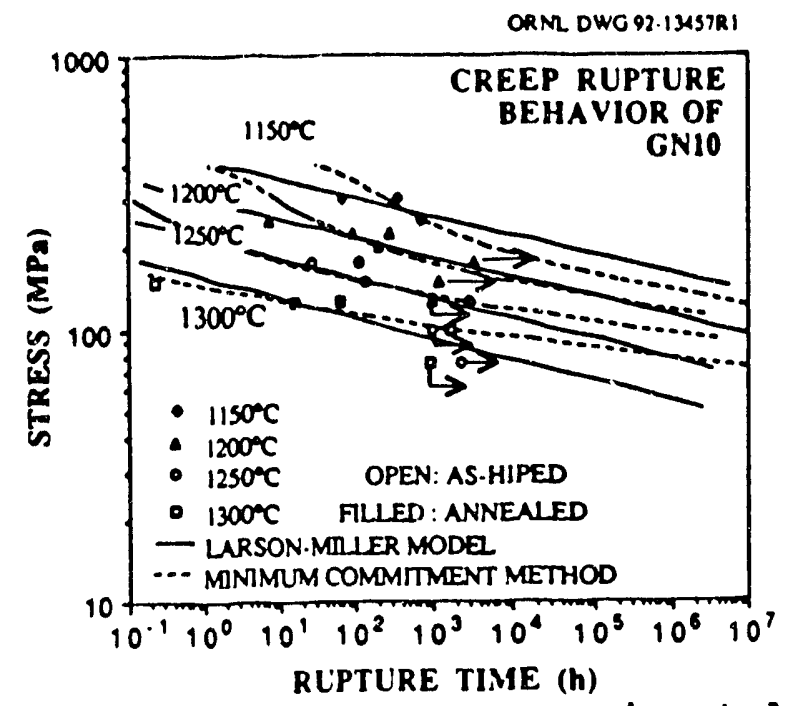

FIG. 8--Comparison of the experimental data and the predictions of the creep rupture life models. For the interrupted tests and those in which the specimens were fractured at the shank as described in the footnote of (Table 1), a rightward arrow was also attached to the corresponding data point implying the actual rupture time might be longer than the indicated one. Also, these data were not used in the regression analysis.

Generally speaking, both models seem to fit the experimental data reasonably well. Results of the regression analysis indicate that the minimum commitment model fits the data slightly better than the Larson-Miller model. This is expected based on the fact that the MC model has five independent variables as opposed to the LM model which only has two.

\section{DEVELOPMENT OF A DEFORMATION AND LIFE PREDICTION MODEL}

The stress exponent and the activation energy terms in Norton's creep relation have been used as indices for distinguishing the creep behavior of various materials. However, the equation has limited capabilities in predicting the overall creep deformation under either simple or complex loading situations. Similarly, although the applications of both the MC and LM models provide reasonable descriptions of the creep rupture behavior of the current material under ldeal laboratory test conditions, i.e., isothermal and constant-load test conditions, they in general can not be extended to practical applications in which both temperature and load vary with time. Therefore, in order to effectively evaluate the mechanical reliability of ceramic components, a realistic deformation and life prediction model for general thermalmechanical loading conditions is necessary. 
Naturally, deformation and fracture mechanisms of advanced $\mathrm{Si}_{3} \mathrm{~N}_{4}$ ceramics are very complicated as temperature increases to a level in the creep range. Therefore, an accurate description of the macroscoplc behavior based on the inherent deformation mechanisms may be very difficult. However, a simplified and reasonable phenomenological model can be contemplated based on behavioral features observed from experimental results combined with intelligent deduction from the information gleaned from micrographs obtained by scanning electron microscopy (SEM) and $x$-ray diffraction (XRD).

Because of the low dislocation activity inside the silicon nitride grains, the main deformation source is from the grain boundary phase. The strong nonlinearity of the creep behavior may suggest that the grain boundary phase of the material has a highly non-Newtonian viscous character associated with both stress and temperature. Results of recent $x$-ray diffraction analysis $[1,14]$ also indicate that the hardening during creep may be mainly due to devitrification of residual amorphous material in the triple points and perhaps in combination with some phase transformations of the grain boundary phases. For creep rupture behavior, it is known that tertiary creep is usually attributed to distributed damage, caused by the nucleation and growth of cavilies or microcracks, which reduces the load bearing capacity of the specimen [15]. The lack of tertiary creep may suggest that eracture was dominated by localized damage from the growth of macrocracks or voids even though other damaging mechanisms may operate concurrently. In fact, very few cavities were observed in the as-HIPed specimen following creep $[1,14]$.

\section{(1) Description of The Model}

The proposed deformation and 1 ife prediction model was formulated on the basis of the following assumptions :

1. The time dependence of the material behavior is mainly attributed to non-Newtonian viscous flow of the residual amorphous phase in the grain boundary, and is a strongly nonlinear function of both stress and temperature,

2. "Hardening", which increases the resistance to both creep deformation and creep crack growth, is enhanced by the progressive devitrification of the residual amorphous phase as temperature and soaking time increase.

3. Although cavity nucleation and growth may occur concurrently, creep fracture is mainly dominated by propagation of the preexisting macrocracks or void formation.

4. No interaction is assumed between creep deformation and damage induced by propagation of macrocracks or cavity nucleation and growth. In other words, there is no acceleratei or tertiary creep due to damage accumulation. 
More specifically, the proposed model is of the following mathematical form.

$$
\begin{gathered}
c=\frac{d t}{d t}=\frac{f\left(\frac{0}{\sigma_{0}}\right) e^{-\frac{\alpha}{\alpha t}}}{\delta}=\frac{\alpha}{\delta}, \\
\delta=\frac{d \delta}{d t}=\frac{\delta_{0}}{\delta} e^{-\frac{\partial_{0}}{d T}}=\frac{\beta}{\delta}, \\
\dot{\omega}=\frac{d \omega}{d t}=\frac{\dot{\omega}_{d}\left(\frac{\sigma}{\sigma_{0}}\right) e^{-\frac{\alpha}{\alpha T}}}{\delta(1-\omega)}=\frac{\gamma}{\delta(1-\omega)} .
\end{gathered}
$$

where

$$
\begin{gathered}
\alpha=f\left(\frac{\sigma}{\sigma_{0}}\right) e^{-\frac{Q_{0}}{k T}}, \\
\beta=\delta_{0} e^{-\frac{Q_{0}}{R T}}, \\
\gamma=\dot{\omega} \alpha\left(\frac{\sigma}{\sigma_{0}}\right)^{v} e^{-\frac{\partial_{0}}{R T}},
\end{gathered}
$$

$\varepsilon$ is the creep strain, $\delta$ is a devitrification variable which takes a value of unity at the initial state but increases as the level of devitrification increases subsequently, $\omega$ is a damage variable which varies from 0 at the initial state to 1 at specimen rupture, $\sigma$ is the stress with $\sigma_{0}$ as a reference stress being set arbitrarily equal to $100 \mathrm{MPa}, T$ is the absolute temperature in $K, R$ is the gas constant, $Q_{b}, Q_{b}, Q_{\omega}, \delta_{0}, m, \omega_{0}$ and $v$ are constants. Since the initial value of 8 for the as-HIPed specimen is $1, \alpha$ is actually the initial creep rate at the inception of creep loading. The function, $f$, indicates the creep rate is stress dependent and strongly nonlinear based on assumption 1. Equation (7b) indicates that the rate of devitrification is a function of soaking temperature and slows inversely as the level of devitrification increases. Under assumption 2, Eqn. (7b) is coupled with Eqns. (7a) and (7c), which, however, are independent of each other because of assumptions 3 and 4 . At the inception of creep loading, no cracks are assumed to have propagated from the initial defects, which are represented by a damage variable with a value of $\omega=0$. The rate of damage, $\omega$, is always positive as time elapses. In terms of crack propagation, $0=1$ may be interpreted as the condition at which the crack reaches its critical size.

\section{(2) Characterization of The Model}

The function $f$ and the material constants in Egns. (7a) and (7b) can be determined by the use of creep data, and those in Eqn. (7c) by the creep rupture life data from both as-HIPed and annealed specimens. The details of the model characterization 
were described in [2]. The function $f$ was determined to be of the following form :

$$
f\left(\frac{\sigma}{\sigma_{0}}\right)=e_{0} \sinh \left(\left(\frac{0-\sigma_{\text {th }}}{100}\right)^{2}\right)
$$

where $\sigma_{\text {th }}$ is the threshold stress below which the creep is assumed to be negligible, is described by

$$
\sigma_{t h}=2.8342 \times 10^{-6} \times 10^{11069 / T_{i}}
$$

and the material constants were determined to be :

$$
\begin{aligned}
& e_{0}=\theta^{62.259} \text { Lor TS } 1200^{\circ} \mathrm{C}, e^{36.035} \text { for } T>1200^{\circ} \mathrm{C} ; \\
& Q_{a}=711.34 \mathrm{~kJ} / \mathrm{mole} \text { for } T \leq 1200^{\circ} \mathrm{C}, 395.51 \mathrm{~kJ} / \mathrm{mole} \text { for } T 1200^{\circ} \mathrm{C} \text {; } \\
& m=0.43 \text {; } \\
& \delta_{0}^{m}=e^{j 8^{4} i} \text { for } T \leq 1200^{\circ} \mathrm{C}, e^{2.62} \text { for T } 7200^{\circ} \mathrm{C} ; \\
& Q_{8}=997.12 \mathrm{~kJ} / \mathrm{mole} \text { for } T s 1200^{\circ} \mathrm{C}, 64.65 \mathrm{~kJ} / \mathrm{mole} \text { for } T 1200^{\circ} \mathrm{C} \text {; } \\
& \dot{\omega}_{0}=e^{110.74}, v=10.86 \text {, and } Q_{0}=1510 \mathrm{~kJ} / \mathrm{mole} \text {. }
\end{aligned}
$$

\section{(3) Evaluation of The Model}

(a) Prediction of creep deformation

(a.1) Isothermal, constant-stress creep--Under isothermal and constant stress conditions, a closed-form solution can be obtained for the creep strain as a function of time as described by the following equation :

$$
e=\frac{\alpha}{m \beta}\left((1+(1+m) \beta t)^{\frac{m}{1+m}}-1\right) \text {. }
$$

Creep curves predicted by Eq. (10) are shown as the solid lines in Figs. 1 to 4 . Examinations of these figures indicate that the essential features of creep behavior are reasonably well described in each case with consideration of the temperature and stress ranges that were covered. It should also be noted that Eqn. (10) has the same form as Eqn. (2).

(a.2) Effects of annealing on subsequent creep behavior-For the annealed specimens, a closed-form solution for the creep strain can again be derived from the model as follows:

$$
e=\frac{\alpha}{m \beta}\left(\left((1+m) \beta t+\delta^{m+1}\right)^{\frac{m}{1+m}}-\bar{\delta}-1 .\right.
$$


where $\bar{\delta}$ is the value of the devitrification variable at the end of annealing given by

$$
\delta=\left(1+(1+m) \beta_{1370^{\circ}} \cdot 150\right)^{\frac{1}{1+0}} .
$$

An example of the predicted results based on Eqn. (11) are shown in Fig. 6 as solid lines. In general, the calculated creep curves overpredicted the experimental creep curves at $T$ $<1250^{\circ} \mathrm{C}$ and vice versa at $\mathrm{T}>1250^{\circ} \mathrm{C}$. Interestingly, the discrepancies in terms of percentage with respect to the measured strain at fracture are about the same regardless of whether specimens were tested in the as-HIPed or annealed condition.

(a.3) Creep under stepwise varied loading--since the model assumes no strain hardening, the creep strain at each loading step can also be calculated using Eq. (11) with $\bar{\delta}$ substituted by the value of $\delta$ evaluated at the end of the previous loading step. The total creep strain is the accumulation of the creep strain resulting from each loading step. Comparisons of calculated and experimental creep curves for a specimen subjected to a single stepped load, depicted in Fig. 5, show that essentiai behavioral features are in qualitative agreement.

ORML DWG 92.134SER1

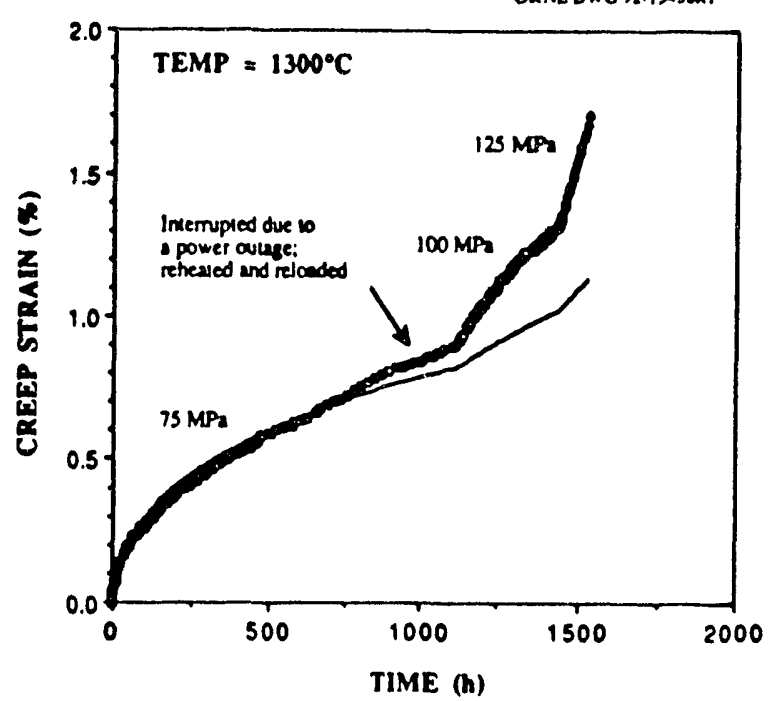

FIG. 9--Comparison between the creep curve of $\mathrm{GN}-10 \mathrm{Si}_{3} \mathrm{~N}$ tested at $1300^{\circ} \mathrm{C}$ under stepwise-varied loading and the solid line predicted by the proposed model. 
Loading at $1300^{\circ} \mathrm{C}$ is shown in Fig. 9. As indicated, the first leg of testing at $75 \mathrm{MPa}$ was interrupted at $t=937 \mathrm{~h}$ due to a power failure. Although the specimen cooled down to ambient temperature, the subsequent creep behavior did not appear to have been altered when testing resumed. The load was increased to $100 \mathrm{MPa}$ after completing $1.125 \mathrm{~h}$ of testing, and further increased to $125 \mathrm{MPa}$ at $t=1437 \mathrm{~h}$, unt1l specimen fracture occurred at $t=1528.82 \mathrm{~h}$. The solid line indicates the predicted creep curve which agrees well with the first segment of the experimental data, but progressively underestimates the remaining data as the applied stress steps upward. One possible reason for the discrepancies may be omission of the interaction between creep deformation and damage accumulation postulated in assumption 4.

(b) Prediction of creep rupture

(b.1) Isothermal, constant-stress creep rupture--Under isothermal and constant-stress condition, the model leads to the following equation for rupture time for both as-HIPed and annealed specimens :

$$
t_{x}=\frac{1}{(1+m) \beta}\left(\left(\frac{m \beta}{2 \gamma}+k-\right)^{\frac{m+1}{m}}-k^{m+1}\right),
$$

where $k$ is the initial value of $\delta$ at the inception of creep loading. Figure 10 shows that predicted rupture-time curves, solid lines for the as-HIPed and dashed for the annealed specimens, compare quite well with experimental data. It is interesting to note that predicted rupture-time curves for each temperature in the pair merge together as the rupture times increase. This observation implies that the effects of annealing on rupture time diminish if tests are run at low stresses over long periods of time. In the short rupture-time range, the dashed curves for 1250 and $1300^{\circ} \mathrm{C}$ turn sharply upward, indicating fast fracture as in short-term tensile tests. The sharp transitions of the rupture curves for 1100 and $1150^{\circ} \mathrm{C}$ will occur outside the plot of Fig. 10 but in the range below $10^{-1} \mathrm{~h}$. This is physically plausible from the view that the stress corresponding to the sharp transition point may fall close to the tensile strength of the material at that temperature. Therefore, any stresses above the transition point bear no physical significance but indicate instant specimen rupture. 


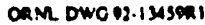

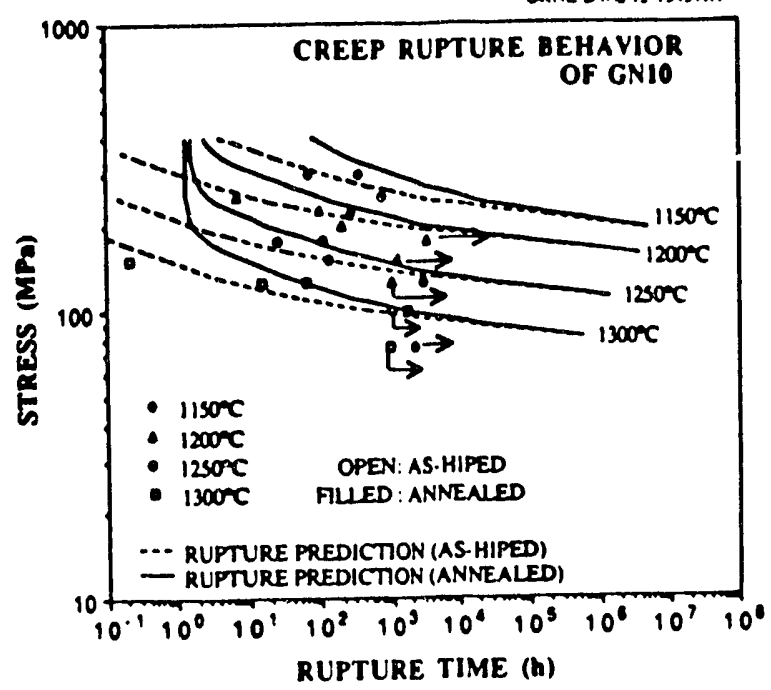

FIG.10--Cor.jarison between the experimental creep rupture times of both the as-HIPed and annealed specimens and the predictions of the proposed model. For the interrupted tests and those in which the specimens were fractured at the shank as described in the footnote of (Table 1), a rightward arrow was also attached to the corresponding data point implying the actual rupture time might be longer than the indicated one.

(b.2) Creep rupture under stepwise varied loading--Under stepwise varied loading conditions, it can be shown that for each loading step, $\omega$ can be calculated from the following expression

$$
\frac{1}{2}(1-\omega)^{2}=\frac{\gamma}{\beta m}\left((1+m) \beta t+k^{1+m}\right)^{\frac{1}{1+m}}-\frac{1}{2}(1-\bar{\omega})^{2}-\frac{\gamma}{m \beta} k \cdots
$$

where $t$ is the time expended at a given step load, and $\bar{\omega}$ is the initial value of $\omega$ when the step load was applied to the specimen. An attempt was made to estimate the rupture time of the specimen tested in the conditions delineated in Fig. 9, using Eqn. (14). Values of $\omega=0.031,0.033$, and 0.103 were obtained at $t=937,1125$, and $1437 \mathrm{~h}$, respectively. Under the last step of loading at $125 \mathrm{MPa}$, the model presicts a rupture time of $239 \mathrm{~h}$, which overpredicts the actual rupture time of $92 \mathrm{~h}$ by $147 \mathrm{~h}$.

\section{(4) Extension of The Model To Multiaxial stress states}

Although the model described above is capable of predicting the creep and creep rupture behavior of ceramic materials under general thermal mechanical loadings, its current scalar form can only be applied to uniaxial stress states such as simple tension or compression. However, in practical applications, nearly all engineering components are subjected to very complicated stress states. Therefore, in order for the 
model to be a truly useful tool for mechanical reliability analysis, its scalar form has to be extended to the tensor form which is valid for multiaxial stress states. As mentioned earlier, for high temperature creep and creep rupture behavior of ceramics, even the tensile data are very limited. Data on of ceramics, even the tensile data ar stresses are virtually
creep behavior under combined data as a guidance, it is
nonexistent. Without experimental dalarial model. very difficult to fully justify a multiaxial model. Nonetheless, a possible approach of extending the above scalar model into a tensorial one may still be contemplated based on the underlying assumptions for model development. As mentioned earlier, creep deformation is assumed to be mainly attributed to non-Newtonian viscous flow in grain boundaries which is driven by shear stress. It then seems reasonable to apply a concept usually employed in the viscoplasticity theory to extend the creep flow equation, 1.e. Eqn.(7a), from scalar form to tensor form through the effective stress and stress deviator which is equivalent to a generic shear stress. On the other hand, since creep fracture is dominated by controlled by macrocracks or voids, damage is expected to be easily realized the maximum principal stress. This can als always perpend

by the fact that the fracture surface is alwa creep test. A icular to the loading direction in a tensilel into a tensor one is therefore proposed as follows:

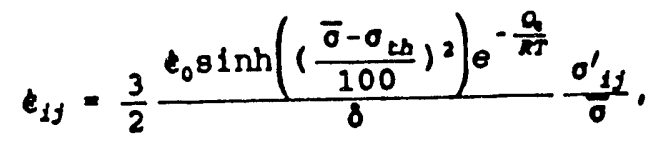

$$
\begin{aligned}
& \delta=\frac{\delta_{0}}{\delta^{n}} e^{-\frac{O_{a}}{R T}} \\
& \dot{\omega}=\frac{\dot{\omega}_{0}\left(\frac{\partial_{\max }}{\sigma_{0}}\right)^{v} e^{-\frac{\partial_{\omega}}{k T}}}{\delta(1-\omega)} .
\end{aligned}
$$

where $\sigma^{\prime}{ }_{i j}=\sigma_{i j}-(1 / 3) \sigma_{k k} \delta_{i j}$ is the stress deviator, $\sigma_{i j}$ is the stress tensor, $\delta_{i j}$ is the kronecker delta, $\sigma_{\max }$ is the maximum principal stress, and $\bar{\sigma}$ is the effective stress defined by

$$
\bar{\sigma}=\sqrt{\frac{3}{2} \sigma_{1 y}^{\prime} \sigma^{\prime}{ }_{1 y}}
$$

Since both the effective stress and the maximum principal stress are reduced to the applied stress in a uniaxial stress state, it can be easily shown that Eqn. (15) is equivalent to Eqn. (7) when applied to uniaxial loading conditions, e.g. simple tension. 


\section{DISCUS8ION}

Until recently, one major issue in the aspect of high temperature engineering design with ceramics has been the lack of experimental data. With the advance of material testing techniques, a reliable data base is gradually growing. However, in addition to the need for continuous improvement of material properties, there seem still to be several other important issues which need to be addressed in the future at least from the viewpoint of engineering analysis and design.

\section{(1) Standard Analysis of Creep And Creep Rupture Data}

Nearly all the creep test data in the literature have been reported through use of Norton's power law relation which was originally proposed for metals. Although the relation itself may be of limited use for deformation prediction, it serves as a valuable tool for distinguishing the creep behavior of different materials. However, as mentioned earlier, for ceramics, because of their lack of tertiary creep or even classical secondary creep, there may not be a common basis to objectively define the creep rate used in Norton's relation, and the values of the stress exponent and the activation energy may vary with the definition of creep rate adopted. Therefore, in order to apply Norton's relation as meaningful indices for the creep properties of different ceramics, some standards seem to be necessary on the definition of creep rate used in Norton's relation for a creep curve without tertiary or secondary stages.

on the other hand, although the $L M$ and $M C$ models are frequently used for describing the creep rupture data of metals under isothermal and constant stress conditions, they are not as popular as Norton's relation for ceramic materials. Perhaps development of some standard creep rupture models, which serves a similar purpose as Norton's relation for creep deformation, may also be helpful for distinguishing the creep rupture behavior of different ceramic materials.

(2) Stochastic Multiaxial Deformation And Life Prediction Model

The importance of a multiaxial deformation and life prediction model has been emphasized earlier. For ceramic materials, in addition to the multiaxial stress states, an ultimate or ideal model also needs to take into account the stochastic nature of creep behavior. For example, in a deterministic approach as used in the curcent model, fracture is assumed to initiate at the point with the highest principal stress. However, in reality, fracture usually depends on the distribution of defects and could be highly stochastic in nature. Therefore, some consideration on the statistics of material behavior are necessary for practical reliability 
analysis. Of course, development of a stochastic model will need a much wider data base.

\section{(3) Experimental Data Under Variable Multiaxial Loadings}

With the increasing maturity of the uniaxial testing technique, one possible future research effort in the area of material testing may be the study of creep behavior of ceramic materials under multiaxial stress state. These data are essential for validating the underlying assumptions for extending the model from uniaxial to multiaxial stress condition such as the use of the effective stress for creep flow equation and maximum principal stress for the damage equation. Some experimental work in this aspect has been reported for room temperature conditions $[16,17]$. There is no doubt that performing this type of experiment at temperatures higher than $1000^{\circ} \mathrm{C}$ is a significant challenge.

It should also be noted that constant stress and temperature are the ideal laboratory test condition. Experimental data obtained under this condition are useful mainly for fundamental material characterization. In practical applications, stress and temperature usually vary with time. Therefore, some experimental data under variable thermal mechanical loadings which can somehow simulate the practical operating condition are also in critical need. These data will not only improve the understanding of material behavior but also serve as a basis for evaluating theoretical models. The test results shown in Fig.10 and the spin disk test [18] may be two possible examples, but more data will be needed in this aspect.

\section{CONCLUSION}

In the current study, a comprehensive set of experimental data on creep and creep rupture behavior of a commercial grade of $\mathrm{Si}_{3} \mathrm{~N}_{4}$ are presented. The data provide a basis for fundamental understanding of the behavior of ceramic materials at elevated temperatures. In addition to the standard analyses of creep and creep rupture data, a multiaxial deformation and life prediction model is also proposed. Despite its simplicity, the model is able to reasonably well describe the essential features of material behavior. With the growth of the material data base, some standards on the creep data analysis methodology for ceramic materials may need to be developed in the future. A challenge for future research in the area of reliability analysis for high temperature ceramics may be in the construction of a stochastic multiaxial deformation and life prediction model in both theoretical development and experimental. verification. 


\section{ACRNOWLEDGEMENTB}

The authors thank Drs. A. E. Pasto and J. H. Schneibel for reviewing the manuscript. This resear $2 h$ was sponsored by the U.S. Department of Energy (USDOE), Assistant Secretary for Conservation and Renewable Energy, office of Transportation Technologies, as part of Ceramic Technology project of Materials Development Program, under contract DE-AC05840 R21400 with Martin Marietta Energy Systems, Inc.

$J$. L. Ding would also jike to acknowledge the partial support provided by the Faculty Research Participation Program administered bv Oak Ridae Associated Universities (ORAU).

\section{REFERENCES}

1. Ding, J. L., Liu, K. C., More, K. L., and Brinkman, C. R." "Creep and Creep Rupture of An Advanced silicon Nitride Ceramic," submitted to J. Am. Ceram. Soc., 1992.

2. Ding, J. L., Liu, K. C., and Brinkman, C. R., "Development of A High Temperature Deformation And Life Prediction Model For An Advanced silicon Nitride Ceramic," submitted to J Am. Ceram. Soc., 1992.

3. Liu, K. C., "Tensile Cyclic Fatigue of structural Ceramics," "Proc. 24th Auto. Tech. Development Contractor's Coordination Meeting, PP. 279-283, 1985.

4. Liu, K. C. and Ding, J. L., "A Mechanical Extensometer For High Temperature Tensile Testing of Ceramics," submitted to ASTM $J$. of Testing \& Evaluation, 1992.

5. Evans, A. G. and Sharp, J. V., "Microstructural studies on Silicon Nitride," J. Mater. Sci., 6, PP. 1292-1302, 1971.

6. Kossowsky, R., "The Microstructure of Hot-Pressed silicon Nitride," J. Mater. Sci., 8, PP. 1603-1615, 1973.

7. Norton, F. H. , "The Creep of Steel at High Temperatures," McGraw-Hill, 1929.

8. Frost, H. J. and Ashby, M. F., Deformation Mechanism Maps - The Plasticity and Creep of Metals and Ceramics, Pergamon Press, 1982.

9. Ferber, M. K. and Jenkins, M. G., "Empirical Evaluation of Tensile creep and creep Rupture in a HIPed silicon Nitride," pp. 81-90 in Creep : Characterization, Damage and Life Assessment, Woodford, D. A., Townley, C. H. A., and Ohnami, M., Eds., ASM International, 1992. 
10. Cranmer, D. C., Hockey, B. J., and Wiederhorn, S. M., "Creep and Creep-Rupture of HIP-ed $\mathrm{Si}_{3} \mathrm{~N}_{4}, "$ Ceram. Eng. sc1. Proc., 1991, (in press).

11. More, Karen, Davis, F, and Carter, C. H., Jr., "A Review nf creep in silicon Nitride and silicon Carbide," pp. 95-125 in Advanced Ceramics, Saito, S., Ed., oxford University Press and Ohmsha Ltd., 1988.

12. Larson, F. R. and Miller, J., "Time-Temperature Relationship for Rupture and Creep Stress," Trans. ASME, Vol. 74, p. 765, 1952 .

13. Manson, S. S. and Muralidharan, U., "Analysis of Creep Rupture Data for Five Multi-heat Alloys by the Minimum Commitment Method Using Double Heat Term Centering," Progressing Analysis of Fatigue and Stress Rupture, pp. $1-46$, MPC-23, ASME, 1984 .

14. More, K. L., Ding, J. L., Liu, K. C., and Brinkman, C. R., "Microstructural Evolution During Creep and creep Rupture of an Advanced Silicon Nitride Ceramic," (in preparation).

15. Ashby, M. F. and Brown, L. M., Perspective in Creep Fracture, Pergamon Press, 1983.

16. Chao, L. Y. and Shetty, D. K., "Reliability Analysis of Structural ceramics subjected to Biaxial Flexure," J. Am. Ceram. Soc., 74(2), PP. 333-344, 1991.

17. Kim, K. T. and Suh, J., "Fracture of Alumina Tube Under Combined Tension/Torsion," J.Am. Ceram. SOC., $75(4)$, PP. 896-902, 1992 .

18. Fang, H. T., Cuccio, J. S., Wade, J. C., and Seybold, $K$. G., "Progress in Life Prediction Methodology for Ceramic Components of Advanced Heat Engines," in Proceedings of the Annual Automotive Technology Development Contractors' Coordination Meeting, Dearborn, Michigan, pp. 261-272, 1991 . 
TABLE 2--Matrix For Creep Tests of GN-10 $81_{3} \mathrm{~N}_{4}$

\begin{tabular}{|c|c|c|c|c|}
\hline & $1150^{\circ} \mathrm{C}$ & $1200^{\circ} \mathrm{C}$ & $1250^{\circ} \mathrm{C}$ & $1300^{\circ} \mathrm{C}$ \\
\hline $50 \mathrm{MPs}$ & & & & $x^{d}(2650 h)$ \\
\hline$\pi 3 \mathrm{MPE}$ & & & $x^{e}(>2238 h)$ & $x^{\circ}(>936.9 h)$ \\
\hline $100 \mathrm{MPE}$ & & & $x^{c}(>1030 h)$ & $x(1721 h)$ \\
\hline $125 \mathrm{MPs}$ & & $x^{a}(>1031 h)$ & $x(2996 h)$ & $x(15.2 h)$ \\
\hline $150 \mathrm{MPa}$ & & $x(1204 h)$ & $x(135.9 h)$ & $x(0.2 h)$ \\
\hline $175 \mathrm{MPa}$ & & $x^{b}(23405 h)$ & $x(25.5 \mathrm{~h})$ & \\
\hline $200 \mathrm{MPa}$ & & $x(203.1 \mathrm{~h})$ & & \\
\hline $225 \mathrm{MPa}$ & & $x(96.3 \mathrm{~h})$ & & \\
\hline $250 \mathrm{MPs}$ & $x(733.8 h)$ & $x(7.5 \mathrm{~h})$ & & \\
\hline \multicolumn{5}{|l|}{$275 \mathrm{MPA}$} \\
\hline $300 \mathrm{MPa}$ & $x(365.4 h)$ & & & \\
\hline
\end{tabular}

Notes:

- Stress increased to $225 \mathrm{MPa}$ after $103 \mathrm{hh}$ of testing.

b. Specimen fractured at the buttonhead due to a power outage.

c. Specimen fractured st the shank.

d. Test is continuing.

e. Specimen was cooled down and unloaded, and then reheated and reloaded at the end of 936.9h. 

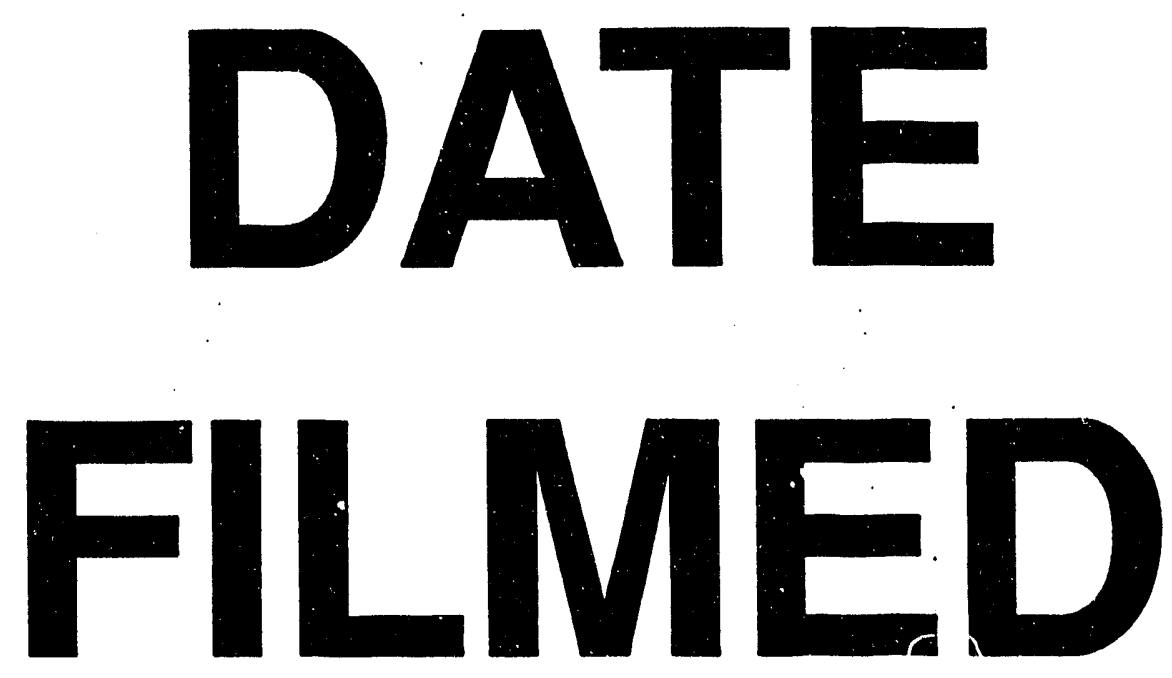

$8 / 17 / 93$
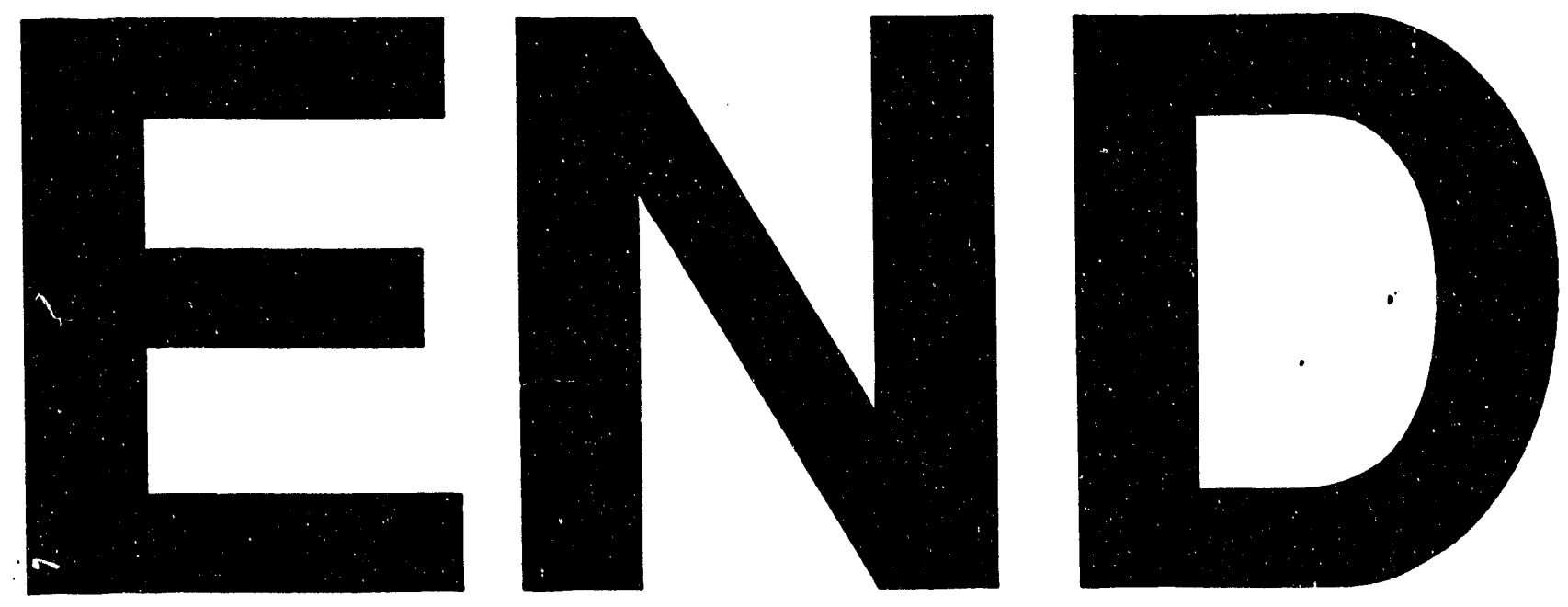
- 